\title{
Os Tribunais comunitários como mecanismos de promoção do pluralismo jurídico e reforço às justiças (in)formais em Moçambique
}

https://doi.org/10.21814/uminho.ed.30.1

\author{
Amadeu Elves Miguel \\ Professor Assistente de Direito Processual Penal \\ na Academia de Ciências Policiais (ACIPOL) - Moçambique
}

\section{Considerações preliminares: os hábitos e costume tradicionais de resolução de conflitos e as legitimidades das justiças comunitárias em Moçambique}

É prática em comunidades moçambicanas, especificamente aquelas distantes do meio urbano, para a resolução de conflitos, seguirem os costumes adotados pelas tribos ou etnias das quais fazem parte ${ }^{1}$. Quaisquer formas de relação, organização social e solução de litígios, estão em conformidade com a cultura ${ }^{2}$, práticas e tradições locais. Grosso modo, essas práticas são reguladas por normas que se mantêm pelo costume ${ }^{3}$ ou pela tradição, com grande diversidade, uma vez que cada grupo tem as suas próprias regras ${ }^{4}$.

Entretanto, desde que Moçambique se estabeleceu como província ultramarina de Portugal (até o ano de 1975), introduziu-se o sistema jurídico da "metrópole", portanto, o sistema jurídico romano-germânico. Contudo, nunca se concluiu a troca do sistema africano pelo europeu, tendo-se apenas comprovado superposições de componentes de um sistema no outro. É assim que Moçambique mantém seus hábitos

1 PEREIRA, Alberto Feliciano Marques - A Arte e a Natureza em Moçambique. Vol. I. Lourenço Marques, no livro não há menção a editor, 1966.

2 A cultura, ainda nas palavras de Jorge MIRANDA abrange a língua e as diferentes formas de linguagem e de comunicação, os usos e Costumes quotidianos, a religião, os símbolos comunitários, as formas de apreensão e de transmissão de conhecimentos (....)" MIRANDA, Jorge - Notas Sobre Cultura, Constituição e Direitos Culturais. Lisboa: “Direito", n. ${ }^{\circ} 138^{\circ}$, IV, 2006.

3 "Costume é o que se faz por hábito, o que se usa habitualmente. Consiste numa série repetida e uniforme de atos ou omissões, com que, por uma espécie de acordo tácito, as populações regulam determinadas relações ou situações jurídicas." PELÁGIO, António - Os Costumes e as Tradições Culturais Como Fundamento da Lei. “Revista do Centro de Investigação Sobre Ética Aplicada (CISEA)”, Angola, n. ${ }^{4}$ - agosto 2013.

4 Importa lembrar que Moçambique tem no mínimo 23 grupos étnicos. 
e costumes de resolução de conflitos e os cidadãos recorrem às chamadas Justiças Comunitárias, para a solução de conflitos.

Em relação à multietnicidade e coabitação desses diferentes mecanismos de solução de conflitos, regra geral, os cidadãos recorrem às justiças comunitárias, sobretudo, autoridades tradicionais, Tribunais Comunitários, entre outras, para a solução de conflitos. Conforme Boaventura de Sousa SANTOS, isto se deve, "por um lado, à natureza fragmentada por várias etnias e culturas dos países africanos, à distância cultural dos sistemas judiciais impostos pela colonização europeia em relação aos cidadãos e a grande diversidade linguística da população" 5 e, acrescentamos nós, à facilidade e simplicidade desses mecanismos tradicionais/justiças comunitárias, bem como à ligação com a cultura das comunidades, o que lhes confere um grande grau de legitimidade.

Por causa dessa legitimidade e do seu papel, ao longo dos tempos, durante a administração colonial, as autoridades tentaram a todo custo - sem sucesso - dissolver o poder da autoridade tradicional. A esse propósito, Sara Araújo, pontua que,

Ainda que a colonização tendesse a endurecer um direito costumeiro e impusesse uma forma de atuação às autoridades tradicionais, nunca conseguiu dominar todos os espaços, pois, houve sempre margens de aversão. As autoridades tradicionais aliadas ao poder colonial não impuseram imprudentemente um direito, com receio de se deslegitimarem totalmente perante a Sociedade. ${ }^{6}$

"Estas são ardilosas" nos dizeres de André José7 ou "elásticas" conforme Van Nieuwaal $^{8}$ e, por isso, encontraram sempre espaços de atuação autónoma e por conseguinte, mantiveram a sua legitimidade.

Como resultado dessa legitimidade das chamadas justiças comunitárias, o "novo Estado", surgido a partir de 1975, reconheceu - ainda que muito tempo depois -, os Tribunais Comunitários, como forma de valorização das justiças comunitárias pelo direito formal/estatal, no âmbito da reforma do sistema judicial ocorrida em 1992, em consequência da revisão constitucional de 1990. Estes tribunais constituem, mecanismos indispensáveis para a viabilização da justiça, sendo tribunais oficiais, uma

5 SANTOS, Boaventura de Sousa - The Heterogeneous State and Legal Pluralism in Mozambique. "Law \& Society Review", 2006, pp. 39-76.

6 ARAÚJO, Sara - Acesso à Justiça e Pluralismo Jurídico em Moçambique. Resolução de litígios no bairro «Jorge Dimitrov». VI Congresso Português de Sociologia. Universidade Nova de Lisboa, Série 62, jun./2008, p. 5-6.

7 JOSÉ, André Cristiano - Autoridades Ardilosas e Democracia em Moçambique. Maputo: “Revista electrónica dos Programas de Mestrado e Doutoramento do CES/FEUC/FLUC”, 2005, Maputo, n. ${ }^{\circ} 1$.

8 NIEUWAAL, E. Van. Adriannn B. van Rouveroy - States and Chiefs. Are chiefs mere puppets? "Journal of Legal Pluralism", 1996, 37-38, pp. 39-78. 
vez criados por lei, mas ao mesmo tempo fora destes ${ }^{9}$, constituindo-se em entidades jurídicas híbridas.

\section{O processo de herança do sistema jurídico português, o panorama geral da organização judiciária no "Novo Estado" e o lugar das justiças comunitárias}

Como se sabe, a evolução dos sistemas jurídicos é consequência de fenómenos de recepção ou transplante, de ordens jurídicas estrangeiras ou passadas ${ }^{10}$. Conforme já referido, "apesar desse fenómeno de transplante jurídico, tanto em Moçambique, como em outros países africanos, nunca se concluiu a troca de um sistema para o outro, tendo-se apenas recorrentemente comprovado superposições de componentes dos diferentes arquétipos jurídicos" ${ }^{11}$. Porém, muito embora desde que Moçambique passou a ser província ultramarina se tenha introduzido, através desse fenômeno de transplante jurídico, o sistema jurídico de Portugal, portanto, o Romano-germânico, a história do direito moçambicano inicia-se à partir do período da proclamação da independência, justamente em 25 de junho de 1975, pois, foi nessa data em que Moçambique se tornou sujeito de Direito Internacional Público, com todos os requisitos necessários de um Estado soberano, nomeadamente, território, povo e poder político.

Com o "novo Estado", de orientação socialista, previu-se a construção de uma sociedade completamente nova. Tratou-se, nos dizeres de Severino NGOENHA e José CASTIANO da primeira república ${ }^{12}$, que se descrevia como pretendente da institucionalização de um sistema judiciário diferente do anterior, que fosse abrangente em todo território e que levasse em conta as formas comunitárias de resolução de conflitos ${ }^{13}$.

Desse modo, a partir das chamadas justiças populares, foi aprovada em 1978 a Lei Orgânica dos Tribunais Populares, Lei n. ${ }^{\circ} 12 / 78$, de 12 de dezembro, que estabelecia que os juízes de carreira, isto é, os formados deveriam trabalhar lado a lado com

9 Há uma questão que deve ser levantada, relativa à função jurisdicional, pois, entendemos que nos termos do n..$^{\circ} 1$ e 2 do art. $212^{\circ}$ da CRM, há imposição de um legalismo excessivo, contrariamente ao art. $2^{\circ}$ e $3^{\circ}$ da Lei n. ${ }^{\circ} / 92$, de 6 de maio, Lei dos Tribunais Comunitários. Em outras palavras, o facto de estes Tribunais serem oficiais, isto é, enxertados no próprio sistema judiciário e ao mesmo tempo estarem fora dele, pode criar uma certa confusão e correr-se o risco de se pôr em causa a essência e os objectivos para os quais esses Tribunais foram criados.

10 VICENTE, Dário Moura - O Lugar Dos Sistemas Jurídicos Lusófonos entre as Famílias Jurídicas. Estudos em homenagem ao Prof. Doutor Martim de Albuquerque. Coimbra, 2010, pp. 401-429. Boaventura SANTOS refere-se a outras designações, tais como, contaminação e infiltração jurídica. SANTOS, Boaventura de Sousa. The Heterogeneous State and Legal Pluralism in Mozambique. "Law \& Society Review", 2006, pp. 39-76.

11 SANTOS, Boaventura de Sousa. The Heterogeneous State and Legal Pluralism in Mozambique. Law \& Society Review, 2006, pp. 39-76.

12 NGOENHA, Severino; CASTIANO, José - Manifesto por uma Terceira Via. Maputo: Real Design, 2019, pp. 3-4.

13 ARAÚJO, Sara e JOSÉ, André Cristiano - Pluralismo Jurídico, Legitimidade e Acesso à Justiça. Instâncias comunitárias de resolução de conflitos no Bairro de Inhagoia "B" - Maputo". Coimbra: "Oficina do CES", 284, 2007. 
aqueles juízes eleitos pela comunidade. Em baixo da pirâmide estavam os tribunais de localidades e de bairros que deviam funcionar só e somente com os juízes eleitos pela comunidade, que iriam julgar pequenas infrações, decidindo na base da concórdia e do bom senso. Com isto, o que o "novo Estado" pretendia era constituir um sistema jurídico unitário, diferente do dualista, com base nas peculiaridades dos usos africanos ${ }^{14}$. Posteriormente a Constituição de 1990 viria a ser revista, tendo sido, em nosso entender, a mais importante revisão, entre todas as constituições, pois trouxe mudanças profundas.

\section{Os Tribunais comunitários como mecanismos de promoção do pluralismo jurídico e reforço das justiças comunitárias}

Conforme visto, os cidadãos recorrem - às formas tradicionais e hábitos locais de resolução de conflito. Os tribunais comunitários surgiram como forma de valorização pelo direito estatal dessas formas tradicionais, no âmbito da reforma do sistema judicial em Moçambique, ocorrida em 1992, como corolário da revisão constitucional de 1990. Estes tribunais foram criados com objetivo de substituir o trabalho que até então era feito pelos chamados tribunais populares, no período de 1978 a 1992.

Os Tribunais Comunitários constituem, portanto, mecanismos indispensáveis para a viabilização da justiça e valorização das formas comunitárias de resolução de conflitos, enxertados no próprio sistema judiciário, sendo tribunais oficiais, uma vez criados por lei, mas ao mesmo tempo fora destes ${ }^{15}$.

Se por um lado, como se disse, estes tribunais têm cobertura e reconhecimento legal na organização judiciária (de base), a lei estabelece que sua operacionalidade funciona fora dessa organização, assente nos valores culturais comunitários. De acordo com o preâmbulo da Lei dos Tribunais Comunitários, "as experiências colhidas pela justiça comunitária indicam para a necessidade da sua valorização e aprofundamento, considerando a diversidade étnica e cultural da sociedade moçambicana." Estes tribunais são entidades jurídicas híbridas em que se levam em consideração princípios do direito estatal e do direito consuetudinário.

No processo da reforma do sistema judicial, em 1992 foi aprovada uma nova lei orgânica dos tribunais judiciais, a Lei n. ${ }^{\circ} 10 / 92$, de 6 de maio. Esta lei instituiu os tribunais distritais como tribunais de base, excluindo deste modo os tribunais de localidade e de bairro (tribunais populares, etc.), como parte do sistema. Todavia, dado

14 TRINDADE, João Carlos - Rupturas e continuidades nos processos políticos e jurídicos. In: SANTOS, Boaventura de Sousa e TRINDADE, João Carlos. Conflito e Transformação Social: uma paisagem das justiças moçambicanas. Vol. II. Porto: Edições Afrontamentos, 2003, pp. 97-128. Vide também GOMES, Conceição; FUMO, Joaquim; MBILANA, Guilherme; SANTOS, Boaventura de Sousa. Os Tribunais Comunitários. In: SANTOS, Boaventura de Sousa e TRINDADE, João Carlos (org.), Conflito e Transformação Social: Uma Paisagem das Justiças em Moçambique. Vol II, Porto: Afrontamento, 2003, pp. 189-340.

15 BUCHILI, Beatriz da Consolação - O Pluralismo Jurídico e a Realidade Sociocultural de Moçambique. Dissertação de Mestrado. Porto Alegre: Faculdade de Direito - Universidade do Rio Grande do Sul, 2006. 
o papel fundamental destes, no mesmo ano, foram criados os Tribunais Comunitários suprindo-se assim a lacuna deixada pelos tribunais populares e de bairro. Por conseguinte, a Lei n. ${ }^{\circ} 4 / 92$, de 06 de maio, criou os Tribunais Comunitários, como parte de instâncias locais de resolução de conflitos, mas fora do sistema judicial.

Em termos de objetivos, estes tribunais têm a responsabilidade de:

a) contribuir para a edificação de um Estado justo;

b) defesa e salvaguarda de direitos fundamentais;

c) estabilidade social e valorização e promoção de hábitos e costumes tradicionais e;

d) demais valores sociais e culturais, conforme estabelecido na lei em referência que os constitui.

Os Tribunais Comunitários porque vieram de certa forma substituir os tribunais populares, acabam tendo que quase a mesma característica, que é conhecerem apenas conflitos de pequena gravidade, cuja solução - prima facie - passa pela reconciliação.

Quanto a sua composição, o n. ${ }^{\circ} 1$ do art. $7^{\circ}$ da lei em referência, indica que os Tribunais Comunitários devem ser constituídos por oito membros, sendo cinco efetivos e três suplentes. Vale mencionar que estes tribunais herdaram um pequeno número de juízes e as infraestruturas que funcionavam os tribunais populares, como foi estabelecido no n. ${ }^{\circ} 2$ do art. $15^{\circ}$ da Lei n. ${ }^{\circ} 4 / 92$, de 06 de maio.

\section{Para concluir}

As peculiaridades históricas e socioculturais de África e de Moçambique concedem forte legitimidade às justiças comunitárias. Com efeito, as diversas formas de justiças comunitárias, de âmbito informal e tradicional mostram-se adequadas, pela proximidade com os cidadãos, celeridade e ajustamentos aos contextos culturais específicos, contrariamente à chamada justiça formal que é considerada bastante "técnica", de difícil acesso, burocrática e, por conseguinte, morosa ${ }^{16}$.

As justiças comunitárias se assentam em princípios culturais e hábitos e costumes aceites e adequados às realidades socioculturais, com baixos custos, que ruflam à mediação e conciliação. Hoje são várias as instâncias de justiças comunitárias em Moçambique.

Entre os vários mecanismos de justiças comunitárias, estão os Tribunais Comunitários, desempenham um importante papel na solução de conflitos locais, quer pela facilitação processual, onde se privilegia a oralidade e a sua "eficiência" na resolução de diferendos.

16 VANDERLINDEN, Jacques - Le pluralisme juridique. In: "Essai de Synthése". Bruxelles: Universite de Bruxelles, 1972, pp. 19-20. 
Nestes tribunais, a resolução de conflitos é rápida e simplificada, levando rapidamente as partes à uma decisão final, num espaço de tempo muito mais curto do que o que normalmente ocorre nos tribunais judicias. A título exemplificativo, o n. ${ }^{\circ} 1$ do artigo $1^{\circ}$ da Lei dos Tribunais Comunitários, diz que: "Os Tribunais Comunitários procurarão que em todas as questões que lhe sejam levadas ao seu conhecimento as partes se reconciliem". Isto mostra que o espírito destes tribunais deve ser o de procurar a reconciliação entre as partes, atuando como tribunais reconciliatórios e não punitivos, tendo por escopo a manutenção da harmonia social nas comunidades.

Na mesma senda, o n. ${ }^{\circ} 2$ do artigo $1^{\circ}$, da mesma lei, ressalva que, "em caso de ausência de consenso os Tribunais Comunitários devem julgar de acordo com a equidade, bom senso e Justiça." Se mesmo assim, prevalecerem controvérsias, o caso será remetido ao tribunal judicial dessa jurisdição ou da jurisdição mais próxima, em função da natureza da controvérsia, para que esta seja analisada e julgada à luz do direito estatal. Como se pode vislumbrar, está aqui patente o princípio da subsidiariedade entre os dois sistemas (comunitário e estatal). 
PEREIRA, Alberto Feliciano Marques - A Arte e a Natureza em Moçambique. Vol. I. Lourenço Marques, s/n, 1966.

MIRANDA, Jorge - Notas Sobre Cultura, Constituição e Direitos Culturais. “Direito”, Lisboa, 2006, n. $138^{\circ}$, IV.

PELÁGIO, António - Os Costumes e as Tradições Culturais Como Fundamento da Lei. "Revista do Centro de Investigação Sobre Ética Aplicada (CISEA)”, Angola, agosto 2013, n. ${ }^{\circ} 4$.

SANTOS, Boaventura de Sousa - The Heterogeneous State and Legal Pluralism in Mozambique: "Law \& Society Review", 2006, pp. 39-76.

ARAÚJo, Sara - Acesso à Justiça e Pluralismo Jurídico em Moçambique. Resolução de litígios no bairro «Jorge Dimitrov». VI Congresso Português de Sociologia. Universidade Nova de Lisboa, Série 62, jun./2008, Série 62.

JOSÉ, André Cristiano - Autoridades Ardilosas e Democracia em Moçambique. Maputo: "Revista electrónica dos Programas de Mestrado e Doutoramento do CES/FEUC/FLUC", 2005, n. ${ }^{\circ} 1$.

NIEUWAAL, E. Van; ROUVEROY, Adrian B. Van - States and Chiefs. Are chiefs mere puppets? "Journal of Legal Pluralism", n. 37-38, pp. 39-78, 1996.

VICENTE, Dário Moura - O Lugar Dos Sistemas Jurídicos Lusófonos entre as Famílias Jurídicas. Estudos em homenagem ao Prof. Doutor Martim de Albuquerque. Coimbra, 2010, pp. 401-429.

SANTOS, Boaventura de Sousa. O Estado Heterógeno e o Pluralismo Jurídico. In: SANTOS, Boaventura de Sousa e TRINDADE, João Carlos. Conflito e Transformação Social: uma paisagem das justiças moçambicanas. Vol. II. Porto: Edições Afrontamentos, 2003.

SANTOS, Boaventura de Sousa - The Heterogeneous State and Legal Pluralism in Mozambique: “Law \& Society Review", 2006, pp. 39-76.

NGOENHA, Severino; CASTIANO, José - Manifesto por uma Terceira Via. Maputo: Real Design, 2019.

ARAÚJO, Sara e JOSÉ, André Cristiano - Pluralismo Jurídico, Legitimidade e Acesso à Justiça. Instâncias comunitárias de resolução de conflitos no Bairro de Inhagoia “B”. Maputo: Coimbra: “Oficina do CES”, 2007, n. ${ }^{\circ} 284$.

TRINDADE, João Carlos - Rupturas e continuidades nos processos políticos e jurídicos. In: SANTOS, Boaventura de Sousa e TRINDADE, João Carlos. Conflito e Transformação Social: uma paisagem das justiças moçambicanas. Vol. II. Porto: Edições Afrontamentos, 2003, pp. 97-128.

GOMES, Conceição; FUMO, Joaquim; MBILANA, Guilherme; SANTOS, Boaventura de Sousa - Os Tribunais Comunitários. In: SANTOS, Boaventura de Sousa e TRINDADE, João Carlos (org.), Conflito e Transformação Social: Uma Paisagem das Justiças em Moçambique. Vol II, Porto: Afrontamento, 2003, pp. 189-340.

BUCHILI, Beatriz da Consolação - O Pluralismo Jurídico e a Realidade Sociocultural de Moçambique. Dissertação de Mestrado. Porto Alegre: Faculdade de Direito - Universidade do Rio Grande do Sul, 2006.

VANDERLINDEN, Jacques - Le pluralisme juridique. In: «Essai de Synthése». Bruxelles: Universite de Bruxelles, 1972, p. 19-20. 